\title{
Phthalocyanine based Schottky solar cells
}

\author{
C. Y. Kwong, A. B. Djurišić \\ Department of Electrical \& Electronic Engineering, University of Hong Kong, \\ Pokfulam Road, Hong Kong \\ L. S. M. Lam, W. K. Chan \\ Department of Chemistry, University of Hong Kong, \\ Pokfulam Road, Hong Kong
}

Phthalocyanine $(\mathrm{Pc})$ materials are commonly used in organic solar cells. Four different phthalocyanines, nickel phthalocyanine ( $\mathrm{NiPc})$, copper phthalocyanine $(\mathrm{CuPc})$, iron phthalocyanine $(\mathrm{FePc})$, and cobalt phthalocyanine $(\mathrm{CoPc})$ have been investigated for organic solar cell applications. The devices consisted of indium tin oxide (ITO) coated glass substrate, Pc layer, and aluminum (Al) electrode. It has been found that ITO/CuPc/Al Schottky cell exhibits the best performance. To investigate the influence of the active layer thickness on the cell performance, cells with several different thicknesses were fabricated and optimal value was found. Schottky cell exhibits optimal performance with one ohmic and one barrier contact. However, it is suspected that ITO/CuPc contact is not ohmic. Therefore, we have investigated various ITO surface treatments for improving the performance of CuPc based Schottky solar cell. We have found that cell on ITO treated with $\mathrm{HCl}$ and UV-ozone exhibits the best performance. AM1 power conversion efficiency can be improved by $30 \%$ compared to cell made with untreated ITO substrate. To improve power conversion efficiency, double or multilayer structure are required, and it is expected that suitable ITO treatments for those devices will further improve their performance by improving the contact between ITO and phthalocyanine layer.

Keywords: organic solar cells, copper phthalocyanine, ITO treatments

\section{INTRODUCTION}

Phthalocyanine (Pc) materials have attracted lots of attention for applications in solar cells, ${ }^{1}$ photodetectors, ${ }^{2}$ gas sensors, ${ }^{3}$ and organic light emitting diodes (OLED) ${ }^{4}$ in the past few decades. In solar cell applications, phthalocyanine materials can be either used alone in a Schottky barrier structure ${ }^{5,6}$ or used together with other n-type materials in a multilayer structure ${ }^{7}$. The highest obtainable power conversion efficiency was $(3.6 \pm 2) \%$ in a multilayer structure under intense AM2 solar irradiation ${ }^{8}$, while the typical power conversion efficiency of Schottky barrier solar cells ranged from $0.001 \%-0.01 \%$. These values are low compared to inorganic solar cells, but organic materials offer the advantages of low fabrication cost and simple fabrication procedure. Therefore, organic materials can offer the opportunity in producing costeffective energy.

Although multilayer solar cells show more promising performance in terms of higher power conversion efficiency, Schottky barrier solar cells are convenient for investigation of the influence of materials properties, active layer thickness, and electrode properties on the solar cells performance. Therefore, we have used Schottky barrier structure in this work to investigate the suitability of four different Pcs in solar cell applications, the thickness dependent power conversion efficiency, and the effects of ITO electrode properties. Solar cells with structure ITO/Pc/Al were fabricated for each Pc on untreated ITO substrate. The thickness of $\mathrm{Pc}$ and $\mathrm{Al}$ was $100 \mathrm{~nm}$ and $60 \mathrm{~nm}$ respectively. We have found that copper phthalocyanine $(\mathrm{CuPc})$ cell exhibits best overall performance. In order to improve the performance, the CuPc layer thickness has been varied from $75 \mathrm{~nm}$ to $150 \mathrm{~nm}$ for determination of the optimal thickness.

In Schottky barrier cells, optimal performance is obtained when active layer forms barrier contact with one electrode and forms ohmic contact with another electrode. In ITO/CuPC/Al cell, the barrier contact is formed at the $\mathrm{CuPc} / \mathrm{Al}$ contact. 
However, in this structure, ITO/CuPc cannot form good ohmic contact as the highest occupied molecular orbital (HOMO) level of $\mathrm{CuPc}$ is about $5.2 \mathrm{eV}$ and the work function of ITO is about $4.5 \mathrm{eV}$. In order to optimize the cell performance, we need to increase the work function of ITO electrode. Various ITO treatments such as plasma treatment ${ }^{9}$ and ultraviolet ozone (UV-ozone) treatment ${ }^{10}$ are confirmed to increase the work function of ITO electrode. Significant amount of research on ITO treatments has been done on organic light emitting diodes (OLEDs). Ishii et. al. ${ }^{11}$ have used combination of ITO treatments to increase its work function. After UV-ozone treatment, ITO substrates have been subjected to argon-50\%oxygen plasma treatment. The plasma was generated at a $100 \mathrm{~W}$ microwave power under $10^{-3}$ torr. They reported ITO work function as high as $6 \mathrm{eV}$. Increase in the ITO work function resulted in lower operating voltage of their OLED. Kim et. al. ${ }^{12}$ also investigated comprehensively the effects of ITO treatments on single and double layer OLED. They found that ITO treated with oxygen-plasma for 10 minutes had the highest work function and improved the OLED performance most significantly. Apart from these dry treatments, there are several aqueous treatments, such as acid and base treatments. Nüesch et. al. ${ }^{13}$ tried several aqueous treatments and found the ITO surface acido basicity was also very important in the performance of organic devices. OLED performance in their work was improved by treating ITO with acid, where ITO was in contact with p-type organic layer. These treatments are widely studied in OLEDs and mostly the improvement is correlated with the increase in ITO work function which causes more efficient charge injection from the ITO to p-type organic materials. However, work on electrode treatments for solar cell applications has been scarce. In our recent work on OLEDs with ITO treatments, ${ }^{14}$ we have obtained some promising results and based on those results we have selected several ITO treatments in ITO/CuPc/Al cells to investigate its effects on the solar cell performance. The best ITO treatment is the combination of UV-ozone treatment and hydrochloric acid $(\mathrm{HCl})$ treatment, which gives a $30 \%$ increase in the power conversion efficiency as compared to the cell made with untreated ITO substrate.

The paper will be organized as follows. In the following section, experimental details are described. In Section 3 , obtained results are presented and discussed. Finally, conclusions are drawn.

\section{EXPERIMENT}

Phthalocyanines including $\mathrm{CuPc}, \mathrm{CoPc}, \mathrm{NiPc}$, and FePc, were bought from Strem Chemicals. ITO coated glass substrates with surface sheet resistance $23.5 \Omega$ /square were supplied by Varitronix Limited, Hong Kong. ITO substrates were first etched to the required pattern by dilute $\mathrm{HCl}$ solution. Before fabrication, they were cleaned thoroughly. First, substrates were rubbed by cotton soaked in acetone and ethanol, respectively. Then the substrates were put in ultrasonic bath in acetone, ethanol and de-ionized water for 10 minutes sequentially. The cleaning process was repeated until the substrates were clean. Finally, substrates were blow dried in nitrogen. Films were evaporated under high vacuum of the order of $10^{-4} \mathrm{~Pa}$. The evaporation rate was kept between $1-2 \AA / \mathrm{s}$. The distance from source to substrates was about $23 \mathrm{~cm}$ to ensure uniformity of film thickness, and the substrate holder was rotating. After evaporation, film thickness was verified by Talistep method. The thickness of the films had been controlled using quartz thickness monitor. The fabricated cells typically consisted of ITO coated substrate as anode, $60 \mathrm{~nm}$ Aluminum (Al) as cathode, and the phthalocyanine layer was sandwiched between the electrodes.

For ITO/CuPc/Al cell with ITO treatment, ITO substrates were treated in different ways, including $\mathrm{HCl}$ treatment, UVozone treatment and combination of UV-ozone and $\mathrm{HCl}$ treatments. In $\mathrm{HCl}$ treatment, the cleaned ITO substrate was immersed in $4 \% \mathrm{HCl}$ solution for one minute. In UV-ozone treatment, the cleaned ITO substrate was put in a UV-lamp box with $20 \mathrm{~W} \mathrm{UV} \mathrm{light} \mathrm{source.} \mathrm{The} \mathrm{distance} \mathrm{between} \mathrm{the} \mathrm{substrate} \mathrm{and} \mathrm{the} \mathrm{UV} \mathrm{light} \mathrm{source} \mathrm{is} \mathrm{about} 12 \mathrm{~cm}$. The treatment was done under the flow of pure oxygen for ten minutes. For combination of UV-ozone and $\mathrm{HCl}(\mathrm{UV}$-ozone $/ \mathrm{HCl})$ treatments, the cleaned ITO was first treated with UV-ozone treatment and then $\mathrm{HCl}$ treatment.

Absorption spectra were measured using Hewlett Packard 8453 UV-VIS spectrometer. Current-voltage characteristics were measured using Keithley 2400 source-measurement unit. The light source used in the measurements was Oriel 66002 Xenon arc lamp with AM1 filter and the cells were illuminated through the ITO contact. 


\section{RESULTS AND DISCUSSION}

Figure 1 shows the absorption spectrum of $\mathrm{CuPc}$. Other metal phthalocyanines have very similar absorption spectra in the visible spectral region, where two distinct absorption bands can be observed, the band around $2 \mathrm{eV}(\mathrm{Q}$ band) and around $3.5 \mathrm{eV}$ (B or Soret band). Both bands have been assigned to $\pi \rightarrow \pi^{*}$ transitions of the macrocyclic $\pi$-system. ${ }^{15-17}$ The energy levels of $\mathrm{Cu}$ d-orbitals are below ligand $\pi$ orbitals by about $4 \mathrm{eV} .{ }^{18}$ Hence, there is little difference between the visible spectra of different metal phthalocyanines.

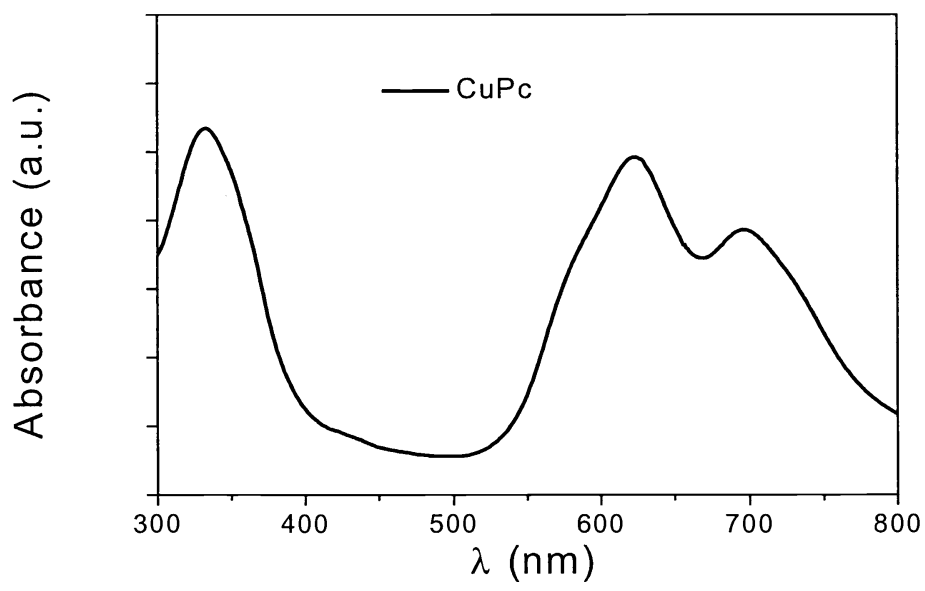

Figure 1. Absorption spectrum of CuPc film

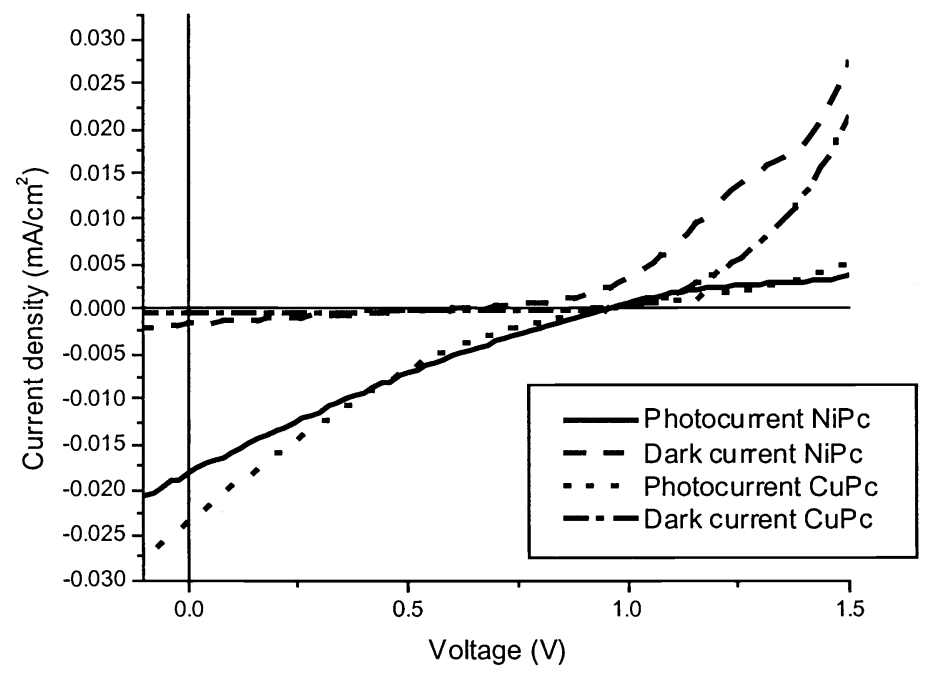

Figure 2. Dark and photocurrent of ITO/CuPc/Al and ITO/NiPc/Al 
Four different phthalocyanines have been investigated for solar cell applications. The phthalocyanine layer is sandwiched between the ITO coated substrate and Al cathode. The thickness of phthalocyanine layer in all devices was equal to $100 \mathrm{~nm}$. Reported power conversion efficiency on $\mathrm{CoPc}$ and FePc Schottky barrier cells are order of magnitude lower than that of $\mathrm{CuPc}$ cell. ${ }^{1}$ In our work, all the cells show photoresponse. However, we have found that the dark current of $\mathrm{CoPc}$ and $\mathrm{FePc}$ is very large. Their dark currents are nearly equal to one-third of the short circuit current. Therefore, $\mathrm{CoPc}$ and $\mathrm{FePc}$ are considered to be unsuitable for solar cell applications. Figure 2 shows the photocurrent and dark current voltage characteristic of $\mathrm{CuPc}$ and NiPc cells. CuPc cell and NiPc cell show similar performance. For NiPc cell, we obtain the open circuit voltage $\mathrm{V}_{\mathrm{oc}}=0.96 \mathrm{~V}$, the short circuit current density $I_{s c}=23.5 \mu \mathrm{A} / \mathrm{cm}^{2}$, and the power conversion efficiency $\eta=0.005 \%$, while for CuPc cell we obtain $\mathrm{V}_{\text {oc }}=0.95 \mathrm{~V}, I_{s c}=23.5 \mu \mathrm{A} / \mathrm{cm}^{2}$, and $\eta=0.004 \%$. However, dark current in NiPc cell is order of magnitude larger than that of $\mathrm{CuPc}$ cell. Therefore, overall performance of $\mathrm{CuPc}$ cell is better than that of $\mathrm{NiPc}$ cell.

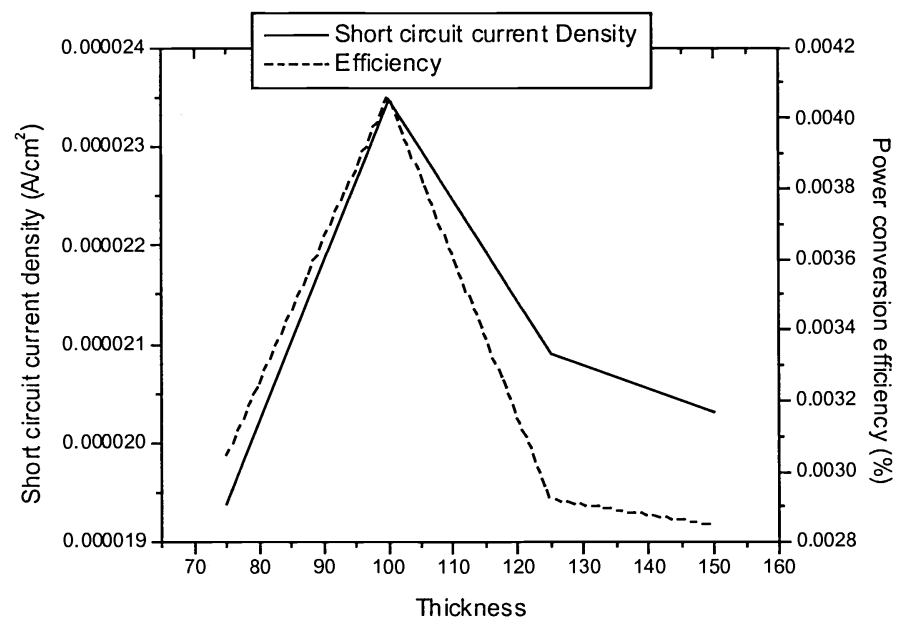

Figure 3. Short circuit current density (Solid line: left axis) and power conversion efficiency (dashed line: right axis) of ITO/CuPc/Al cells with different $\mathrm{CuPc}$ film thickness.

$\mathrm{CuPc}$ has been chosen for the investigation of thickness dependent power conversion efficiency. Thickness of the CuPc layer was varied from $75 \mathrm{~nm}$ to $150 \mathrm{~nm}$. Cells were illuminated through the ITO contact with $98 \mathrm{~mW} / \mathrm{cm}^{2}$ AM1 solar irradiation. Figure 3 shows short circuit current density and power conversion efficiency versus CuPc film thickness in ITO/CuPc/Al cells. For cell with thin CuPc film $(75 \mathrm{~nm})$, the current density is low, $19.4 \mu \mathrm{A} / \mathrm{cm}^{2}$. It is due to the lack of solar energy absorption leading to less excitons generated. Therefore, less charge carriers are generated by excitons dissociation resulting in low short circuit current density. For $125 \mathrm{~nm}$ cell, the short circuit current density $\left(21.0 \mu \mathrm{A} / \mathrm{cm}^{2}\right)$ is larger than that of $75 \mathrm{~nm}$ cell. It is caused by increased solar energy absorption. Thus, more excitons are generated. This gives rise to more charge carriers generated and an increase in current density. For $150 \mathrm{~nm}$ cell, the short circuit current density is $20.3 \mu \mathrm{A} / \mathrm{cm}^{2}$. Compared to the value obtained from $125 \mathrm{~nm}$ cell, this value is lower even though more solar energy is absorbed. Loutfy and Sharp ${ }^{19}$ reported the relation between photovoltaic action spectra and the illumination direction. They found that the action spectrum matched well with the absorption spectrum when the device was illuminated through the barrier contact. While the photovoltaic spectrum matched to the transmittance spectrum when it was illuminated through the ohmic contact. As we have illuminated the cell through ITO (the ohmic contact), less portion of solar energy can be transmitted to the depletion region in the device. This reduces the amount of excitons generated in the depletion region. Moreover, it is expected that excitons generated outside the depletion region are unlikely to dissociate into charge carriers 
because of short exciton diffusion length. Therefore, less charge carriers are generated resulting in lower short circuit current density. In this work, we have found optimal thickness of $100 \mathrm{~nm}$ for ITO/CuPc/Al cell, giving a $23.5 \mu \mathrm{A} / \mathrm{cm}^{2}$ short circuit current and $0.0040 \%$ power conversion efficiency under intense AM1 solar irradiation.

For Schottky barrier solar cell, optimal performance can be obtained when there is one barrier contact and one ohmic contact. In ITO/CuPc/Al Schottky cell, the barrier is formed at the CuPc/Al contact. However, ITO and CuPc cannot form good ohmic contact because the HOMO level of $\mathrm{CuPc}$ is about $5.2 \mathrm{eV}$ and the work function of ITO electrode is about 4.5-4.8 eV. Therefore, there is at least $0.4 \mathrm{eV}$ barrier formed between CuPc and ITO. The energy diagram is shown in Figure 3.

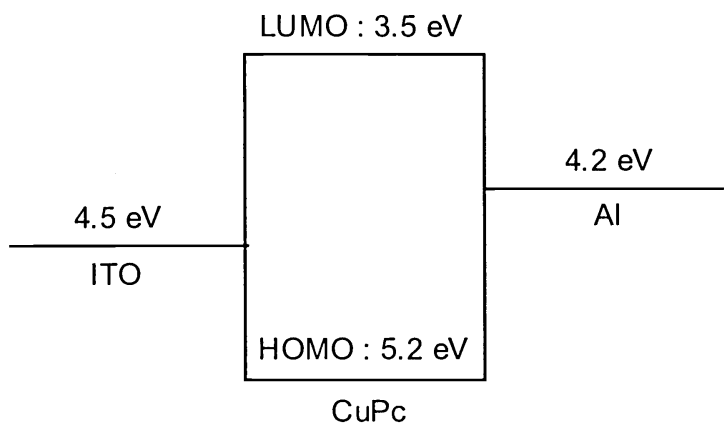

Figure 3. Energy diagram of ITO/CuPc/Al cell

In order to optimize cell performance, the barrier at ITO/CuPc contact must be reduced. In other words, ITO work function must be increased. According to our previous work investigating the effects of several ITO treatments on the performance of OLED, ${ }^{14}$ we have found that the two layer OLED exhibited significant better performance when the ITO substrate was treated with $\mathrm{UV}$-ozone $/ \mathrm{HCl}$ treatment. Therefore, we have selected $\mathrm{HCl}$ treatment, the commonly used UVozone treatment, and the combination of them in this work.

Figure 4 shows the photocurrent-voltage characteristic of ITO/CuPc/Al cells subjected to different ITO treatments together with the untreated one and Table 1 summarizes the parameters characterizing the solar cells with different ITO treatments. When only $\mathrm{HCl}$ treatment is used, the observed short circuit current is increased. However, the open circuit voltage is decreased and the rectifying behavior is worsened. When only UV-ozone treatment is used, the short circuit current is also increased, but only slightly. However, when UV-ozone treatment is used in combination with $\mathrm{HCl}$ treatment, the open circuit voltage is increased from $0.94 \mathrm{~V}$ to $0.99 \mathrm{~V}$ and the short circuit current is increased from $23.5 \mu \mathrm{A} / \mathrm{cm}^{2}$ to $28.9 \mu \mathrm{A} / \mathrm{cm}^{2}$. This results in an increase of power conversion efficiency from $0.0040 \%$ to $0.0052 \%$. The increase in the short circuit current in all the treatments can be attributed to the improvement of the contact on the ITO side. However, exact mechanism of the improvement of the performance is not fully clear. ITO treatments have been proven to change the work function, surface sheet resistance, and surface roughness of the ITO substrates. All these parameters can play a role in the device performance. Sheet resistance of the ITO affects the short circuit current, but it does not affect open circuit voltage. The observed changes in the open circuit voltage are likely to be correlated with the changes in the work function though the exact relation between the ITO work function and the solar cell open circuit voltage is not clear from the experimental results. Further studies on the surface morphology of the phthalocyanine films grown on treated ITO substrates are needed to investigate how the electrode treatments influence the subsequent growth of the organic material. 


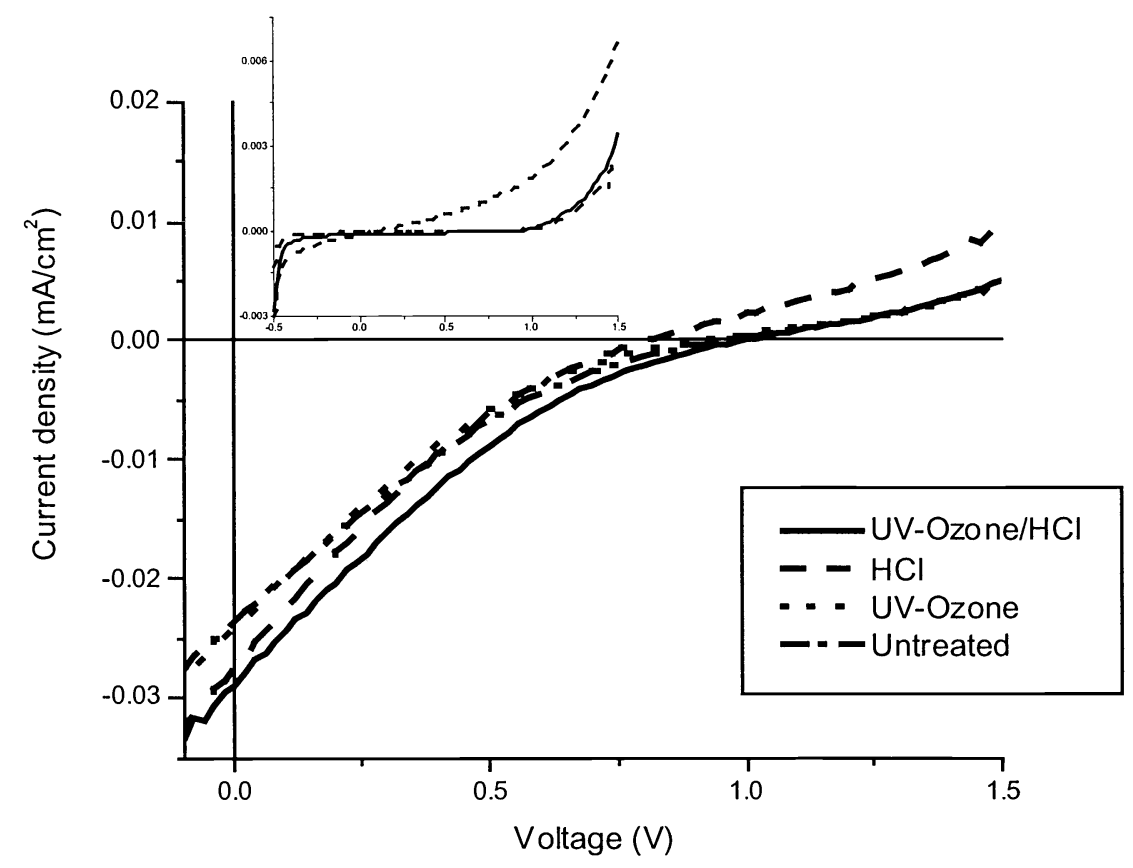

Figure 4. Photocurrent-voltage characteristic of CuPc cells with different ITO treatments. Inset shows the corresponding dark current voltage characteristic of these cells.

\begin{tabular}{|l|c|c|c|c|}
\hline \multicolumn{1}{|c|}{ ITO treatment } & $\mathrm{J}_{\mathrm{sc}}\left(\mu \mathrm{A} / \mathrm{cm}^{2}\right)$ & $\mathrm{V}_{\mathrm{oc}}(\mathrm{V})$ & Fill Factor & $\eta(\%)$ \\
\hline Untreated & 23.5 & 0.94 & 0.18 & 0.0040 \\
\hline $\mathrm{HCl}$ & 27.3 & 0.80 & 0.19 & 0.0042 \\
\hline UV-Ozone & 24.1 & 0.90 & 0.17 & 0.0038 \\
\hline UV-Ozone/HCl & 28.9 & 0.98 & 0.18 & 0.0052 \\
\hline
\end{tabular}

Table 1. Comparison of solar cells parameters for different ITO treatments. Cells were illuminated through ITO contact with $98 \mathrm{~mW} / \mathrm{cm}^{2}$ AM1 excitation.

Increase in the ITO work function by ITO surface has been reported. ${ }^{11-14}$ However, the mechanisms behind are different. For UV-ozone or oxygen plasma treatment, the increase in work function is attributed to the removal of surface carbon contamination. ${ }^{20}$ For acid treatment, the mechanism of the increase in work function is different. It has been attributed to the protonation of the ITO surface, with remaining anion likely assembling on the top of adsorbed protons, thus producing surface dipole and vacuum level shift. ${ }^{21}$ Apart from this, other parameters such as sheet resistance and surface roughness are also affected by the ITO treatments. Therefore, not all treatments can cause an improvement in solar cell performance even though the barrier in ITO/CuPc contact has been reduced. If acid treatment is performed without previous cleaning of the surface with oxygen plasma, ${ }^{20}$ or UV ozone as in this work, it is possible that the residue from chemical reactions between acid and surface contaminants would modify the growth of organic layer and contribute significantly to impurities and pinhole defects, thus causing higher current both in the light and in the dark, and lower open circuit voltage for $\mathrm{HCl}$ only treated cell. When ITO is treated with $\mathrm{UV}$-ozone/ $\mathrm{HCl}$ treatment, the rectification properties are similar to the 
cell treated with UV ozone only, but significantly better than the cell treated with $\mathrm{HCl}$ only. The short circuit current under irradiation is improved. This is likely due to the improved contact between ITO and CuPc, resulting in overall improvement in the cell efficiency.

\section{CONCLUSION}

In conclusion, we have compared the suitability of four different phthalocyanines, namely $\mathrm{CuPc}, \mathrm{CoPc}, \mathrm{FePc}, \mathrm{NiPc}$ for solar cell applications. We have found that $\mathrm{FePc}$ and $\mathrm{CoPc}$ are not suitable in solar cell applications due to the large dark current. NiPc and CuPc cells show similar performance in terms of power conversion efficiency while CuPc cell exhibits lower dark current. Different thicknesses of the active layer have been investigated, and the highest efficiency has been obtained for $100 \mathrm{~nm}$ thick CuPc layer. This optimal thickness has been used for investigating the effects of ITO properties on solar cell performance. Among all ITO treatments, the combination of UV-ozone and $\mathrm{HCl}$ treatments have given the most promising results. The power conversion efficiency is $0.0052 \%$, which is $30 \%$ higher than that of the optimized CuPc cell without any ITO treatment. Compared to that reported in the literature, ${ }^{1}$ this value is already five times higher than previously reported. The improvement is attributed to the improved ITO/CuPc contact. It is expected that similar improvement in the performance will also be observed in the multilayer solar cells.

\section{ACKNOWLEDGEMENTS}

This work has been supported by the RGC earmarked grant of Hong Kong (Project HKU 7096/00P and HKU 7075/01P) and the University of Hong Kong University Research Committee grant.

\section{REFERENCES}

1. C. C. Leznoff and A. B. P. Lever, Ed., Phthalocyanines. Properties and Applications, pp. 219-284, VCH Publishers Inc., New York, 1996.

2. P. Penumans, V. Bulović and S. R. Forrest, "Efficient, high-bandwidth organic multiplayer photodetectors", Appl. Phys. Lett. 76, pp. 3855-3857, Jun. 2000.

3. J.C. Hsieh, C. J. Liu and Y. H. Ju, "Response characteristics of lead phthalocyanine gas sensor: effects of film thickness and crystal morphology", Thin Solid Films 322, pp. 98-103, Jun. 1998.

4. H. Vestweber and W. Rieß, "Highly efficient and stable organic light-emitting diodes", Synthetic Metals 91, pp. 181185, Dec. 1997.

5. R. O. Loutfy, J. H. Sharp, C. K. Hsiao, and R. Ho, "Phthalocyanine organic solar cells. Indium/x-metal free phthalocyanine Schottky barriers", J. Appl. Phys. 52, pp. 5218-5230, Aug. 1981.

6. Rudiono, S. Okazaki, M. Takeuchi, "Effects of $\mathrm{NO}_{2}$ on photovoltaic performance of phthalocyanine thin film solar cells", Thin Solid Films 334, pp. 189-191, Dec. 1998.

7. C. W. Tang, "Two-layer organic photovoltaic cell”, Appl. Phys. Lett. 48, pp. 183-185, Jan. 1986.

8. P. Peumans and S. R. Forrest, "Very-high-efficiency double-heterostructure copperphthalocyanine/ $\mathrm{C}_{60}$ photovoltaic cells", Appl. Phys. Lett. 79, pp. 126-128, Jul. 2001.

9. K. Furukawa, Y.Terasaka, H. Ueda and M. Matsumura, "Effect of a plasma treatment of ITO on the performance of organic electroluminescent devices", Synthetic Metals 91, pp. 99-101, Dec. 1997.

10. M. G. Mason, L. S. Hung and C. W. Tang, S. T. Lee, K. W. Wong and M. Wang, "Characteriaztion of treated indiumtin-oxide surfaces used in electroluminescent devices”, J. Appl. Phys. 86, 99.1688-1692, Aug. 1999.

11. M. Ishii, T. Mori, H. Fujikawa, S. Tokito and Y. Taga, "Improvement of organic electroluminescent device performance by in situ plasma treatment of indium-tin-oxide surface", Journal of Luminescence 87-89, pp. 1165-1167, May 2000.

12. J. S. Kim, M. Granström, R. H. Friend, N. Johansson, W. R. Salaneck, R. Daik, W. J. Feast and F. Cacialli, "Indiumtin-oxide treatments for single- and double-layer polymeric light-emitting diodes: The relation between the anode physical, chemical, and morphological properties and the device performance”, J. Appl. Phys. 84, pp. 6859-6870, Dec. 1998. 
13. F. Nüesch, E. W. Forsythe, Q. T. Le, Y. Gao, and L. J. Rothberg, "Importance of indium tin oxide surface acido basicity for charge injection into organic materials based light emitting diodes", J. Appl. Phys. 87, pp. 7973-7980, June 2000.

14. A. B. Djurišić, T. W. Lau, C. Y. Kwong, W. L. Guo, Y. Bai, E. Herbert Li, and W. K. Chan, "Surface treatments of indium-tin-oxide substrates: comprehensive investigation of mechanical, chemical, thermal, and plasma treatments", Proc. SPIE $46^{\text {th }}$ annual meeting, San Diego, 2001.

15. B. H. Schechtman and W. E. Spicer, "Near infrared to vacuum ultraviolet absorption spectra and the optical constants of phthalocyanine and porphyrin films", J. Mol. Spectr. 33, pp. 28-48, 1970.

16. A. Ritz and H. Lüth, "The electronic structure of GaP (110) and Cu-phthalocyanine overlayers studied by ellipsometry", Appl. Phys. A 31, pp. 75-80, 1983.

17. L. Edwards and M. Gouterman, "Porphyrins. XV. Vapor absorption spectra and stability: Phthalocyanines", J. Mol. Spectr. 33, pp. 292-310, 1970.

18. M. Iwan, E. E. Koch, T. C. Chiang, D. E. Eastman, F. J. Himpsel, "Multielectron effects in photoemission from quasiatomic copper in Cu-phthalocyanine", Solid State Commun. 34, pp. 57-60, 1980.

19. R. O. Loutfy and J. H. Sharp, "Photovoltaic properties of metal-free phthalocyanine. I. Al/ $\mathrm{H}_{2} \mathrm{Pc}$ Schottky barrier solar cells", J. Chem. Phys. 71, pp.1211-1217, Aug. 1979.

20. K. Sugiyama, H. Ishii, Y. Ouchi, and K. Seki, "Dependence of indium-tin-oxide work function on surface cleaning method as studied by ultraviloet and x-ray photoemission spectroscopies", J. Appl. Phys. 87, pp. 295-298, Jan. 2000.

21. F. Nüesch, L. J. Rothberg, E. W. Forsythe, Q. T. Le, and Y. Gao, "A photoelectron study on the indium tin oxide treatment by acids and bases", Appl. Phys. Lett. 74 pp. 880-882, Feb. 1999. 